\title{
Aggressiveness in depression: A neglected symptom possibly associated to bipolarity and mixed features
}

\section{Running title: aggressiveness in mixed depression}

Norma Verdolini ${ }^{1,2}$, Giulio Perugi ${ }^{3}$, Ludovic Samalin ${ }^{1,4,5}$, Andrea Murru ${ }^{1}$, Jules Angst ${ }^{6}$, Jean-Michel Azorin ${ }^{7}$, Charles L. Bowden ${ }^{8}$, Sergey Mosolov ${ }^{9}$, Allan H. Young ${ }^{10}$, Margherita Barbuti ${ }^{1,3}$, Giovanni Guiso ${ }^{1,11}$, Dina Popovic ${ }^{1,12}$, Eduard Vieta ${ }^{1 *}$, Isabella Pacchiarotti ${ }^{1}$ for the BRIDGE-II-Mix Study Group

1 Bipolar Disorders Unit, Hospital Clinic, Institute of Neurosciences, University of Barcelona, IDIBAPS, CIBERSAM, c/Villarroel, 170, 12-0, 08036, Barcelona, Catalonia, Spain

${ }^{2}$ Division of Psychiatry, Clinical Psychology and Rehabilitation, Department of Medicine, University of Perugia, Santa Maria della Misericordia Hospital, Edificio Ellisse, 8 Piano, Sant'Andrea delle Fratte, 06132, Perugia, Italy

${ }^{3}$ Department of Experimental and Clinic Medicine, Section of Psychiatry, University of Pisa, Via Roma 67, 56100, Pisa, Italy

${ }^{4} \mathrm{CHU}$ Clermont-Ferrand, Department of Psychiatry, EA 7280, University of Auvergne, 58, Rue Montalembert, 63000, Clermont-Ferrand, France

${ }^{5}$ Fondation FondaMental, Hôpital Albert Chenevier, Pôle de Psychiatrie, 40 rue de Mesly, 94000, Créteil, France

${ }^{6}$ Psychiatric Hospital, University of Zurich, Switzerland

${ }^{7}$ AP HM, Psychiatric Pole, Sainte Marguerite, Marseille, France

${ }^{8}$ Department of Psychiatry, University of Texas Health Science Center at San Antonio, San Antonio, TX, USA

${ }^{9}$ Department for Therapy of Mental Disorders, Moscow Research Institute of Psychiatry, Moscow, Russia

${ }^{10}$ Centre for Affective Disorders, Department of Psychological Medicine, Institute of Psychiatry, Psychology \& Neuroscience, King's College London, London, UK.

${ }^{11}$ Department of Medical Sciences and Public Health, University of Cagliari and Psychiatric Clinic, University Hospital, Cagliari, Italy

${ }^{12}$ Psychiatry B, The Chaim Sheba Medical Center, Ramat-Gan, Israel

\section{Corresponding author:}

Prof. Eduard Vieta

Telephone: +34 932275400 ext. 3130

Fax: +34 932279228

e-mail: EVIETA@clinic.cat

Address: Bipolar Disorders Unit, Institute of Neuroscience, IDIBAPS CIBERSAM Hospital

Clínic de Barcelona, c/Villarroel, 170, 12-0, 08036 Barcelona (Spain) 


\section{Abstract}

Objective: To evaluate aggressiveness during a major depressive episode (MDE) and its relationship with bipolar disorder (BD) in a post-hoc analysis of the BRIDGE-IIMIX study.

Method: A total of 2,811 individuals were enrolled in this multicenter cross-sectional study. MDE patients with (MDE-A, $n=399$ ) and without aggressiveness (MDE-N, $\mathrm{n}=2,412$ ) were compared through Chi-square test or Student's t-test. A stepwise backward logistic regression model was performed.

Results: MDE-A group was more frequently associated with $\operatorname{BD}(p<0.001)$ whilst aggressiveness was negatively correlated with unipolar depression $(\mathrm{p}<0.001)$. At the logistic regression aggressiveness was associated with: the age at first depressive episode $(p<0.001)$; the severity of mania $(p=0.03)$; the diagnosis of $B D(p=0.001)$; comorbid borderline personality disorder $(\mathrm{BPD})(\mathrm{p}<0.001)$ but not substance abuse ( $\mathrm{p}=0.63)$; no current psychiatric treatment $(\mathrm{p}<0.001)$; psychotic symptoms $(\mathrm{p}=0.007)$; the marked social/occupational impairment $(\mathrm{p}=0.002)$. The variable most significantly associated with aggressiveness was the presence of DSM-5 mixed features $(\mathrm{p}<0.001$, $\mathrm{OR}=3.815$ ). After the exclusion of $\mathrm{BPD}$, the variable of lifetime suicide attempts became significant $(\mathrm{p}=0.013$, $\mathrm{OR}=1.405)$.

Conclusion: Aggressiveness seems to be significantly associated with bipolar spectrum disorders, independently from BPD and substance abuse. Aggressiveness should be considered as a diagnostic criterion for the mixed features specifier and a target of tailored treatment strategy.

Keys words: aggressiveness, bipolar disorder, DSM-5 mixed features specifier, major depressive episode 


\section{Significant outcomes}

In this post-hoc analysis of the BRIDGE-II-MIX study, the presence of aggressive behaviors was mainly related with socio-demographic and clinical characteristics associated with bipolarity.

The most relevant clinical variable associated with aggressiveness during a major depressive episode was the presence of mixed features.

The identification of aggressive behaviors could be the target of a tailored treatment strategy in this subgroup of bipolar disorder patients.

\section{Limitations}

There is a possible bias due to the fact that the psychiatrists involved in the study were those with a particular interest in bipolar disorder.

This is a post-hoc analysis of the BRIDGE-II-Mix study, whose primary aim was not aggressiveness.

The retrospective assessment of aggressiveness avoided to explain causality and could possibly lead to self-report bias 


\section{Introduction}

Aggressiveness is defined as an overt behavior involving intent to inflict noxious stimulation or to behave destructively towards another organism or object (1). In psychiatry, it is a behavioral or motor response associated with intent to do harm and it may be self-directed (2).

Several psychiatric disorders, including mood disorders, have been associated with increased rates of aggressiveness and violent behaviors (3). Particularly, bipolar disorder (BD) patients presented increased risk for aggressive behaviors $(4,5)$. Indeed, aggressiveness has assumed particular importance as a core feature of manic and mixed states (6), independently from psychosis (7), and often emerging as a correlate of comorbid substance abuse and suicidality (8).

In comparison with subjects with no-BD, but suffering from other psychiatric disorders, and healthy controls, BD patients showed in previous studies increased selfreported verbal and physical aggressiveness, particularly during acute episodes and independently from BD subtypes, severity and polarity of the current episode, psychotic symptoms and current pharmacological treatments $(4,9)$. In addition, manic patients showed the highest odds ratio for aggressive incidents among psychiatric inpatients (10).

As for trait characteristics of depressive episodes, it has been found that BD-I and BD-II depressed patients had more life-time aggressiveness/hostility than unipolar depressed patients (11).

Previous studies have shown that comorbidity with other disorders, namely substance and alcohol abuse and borderline personality disorder (BPD), increased the risk of aggressiveness in BD patients $(12,13)$. 
Several factor analyses described the clinical context of aggressiveness in mania. Aggressiveness was associated with paranoia and irritability, loading on the same factor (“irritable aggressiveness”) (14). In another factor analysis, aggressiveness loaded on the same factor as irritability, uncooperativeness, impatience and lack of insight, suggesting the existence of a distinct subtype of mania defined as "aggressive” (7). In a more recent study, the factor analysis revealed 5 factors, and one of them was termed “'Dysphoria', with positive significant loading for hostility, uncooperativeness, and suspiciousness, representing one of the two classical aspects of manic states (15). In this context, aggressiveness could represent a core feature of manic and mixed episodes of $\mathrm{BD}$, and might be a persistent trait in the sense of appearing in the same patients across repeated episodes.

Despite these previous findings, aggressiveness is not currently considered as a DSM diagnostic criterion of mania and consequently is not included in the DSM-5 mixed features in both bipolar and unipolar depressive episodes (16). In fact, only irritable mood represents a major defining characteristic of manic episodes since the first edition of DSM (17) and across the different revisions of the manual up to the last DSM-5. The DSM-5 fails to include the most common symptoms of mixity, including anxiety, agitation, and irritability as criteria for mixed features $(18,19)$.

Few studies between those mentioned above evaluated possible clinical correlates of aggressiveness during a major depressive episode (MDE) across mood disorders. These studies were conducted on small samples of patients or derived only from one psychiatric center. 


\section{Aims of the study}

The aim of the present post-hoc analysis was to assess the relationship between BD diagnosis or features and the presence of aggressive behaviors during a major depressive episode. We explored the possible clinical and treatment implications of this association.

\section{Material and methods}

Sample and assessment

This study is a post-hoc analysis of the BRIDGE-II-Mix study. The general methodology of the BRIDGE-II-MIX study was described in detail in previous reports (20-23). The BRIDGE-II-Mix study was a multicenter, international, noninterventional, cross-sectional study. It was conducted between June 2009 and July 2010 in 239 centers in Bulgaria, Egypt, Morocco, the Netherlands, Portugal, Russia, Spain, and Turkey where hospital-based or community psychiatrists were expected to enroll consecutively 10-20 eligible adult patients aged 18 or older consulting for a MDE according to the Diagnostic and Statistical Manual of Mental Disorders-IV edition (DSM-IV) criteria during a three month recruitment period.

The selection of the different centers in each country would reflect the psychiatric healthcare provision and the patient care typical of the country's practice and regional diversity. Each center collected anonymous screening logs of the patients. Reasons for nonparticipation were pre-coded (refusal to participate, patient unable to complete the questionnaire, and other). Patients presenting with an acute nonpsychiatric condition/emergency were excluded.

From the 239 psychiatrists involved in the study, 237 returned their site questionnaire. A total of 2,811 patients agreed to participate and provided complete 
data, representing the full analysis population. Demographic features were generally similar across countries.

The study was conducted according to the Declaration of Helsinki (Hong Kong Amendment; http://www.wma.net) and the Good Epidemiology Practice and the International Epidemiologic Association (IEA) European Federation (http://ieaweb.org). Good Epidemiologic Practice (GEP)-IEA Guidelines were followed for proper conduct of epidemiologic research, as well as pertinent national, legal and regulatory requirements. Written informed consent was obtained from each patient. In each country, the protocol was approved by the local ethics committee.

\section{Data collection}

For each patient, the psychiatrists completed a case report, incorporating inclusion criteria, socio-demographic variables (age, gender, marital status), inpatient or outpatient status, history of psychiatric symptoms (mood symptoms, postpartum depression, suicide attempts), and previous psychiatric hospitalizations. Features of the MDE, including bipolar symptoms listed in the DSM-IV-TR (24) diagnostic criteria for BD, known risk factors for BD (e.g., family history of BD and postpartum depression), previous response to antidepressants, psychiatric comorbidity, current treatment were recorded. The functional status was determined by the investigator using the Global Assessment of Functioning (GAF) (25) and the global illness severity was assessed through the Clinical Global Impression-Bipolar Version (CGI-BP) (26).

The evaluation packet was explicitly structured to use skills that fully trained psychiatrists would have and routinely apply in conducting an initial evaluation of an acutely ill patient. No rating scales requiring calibration with a standard were incorporated. Raters were instructed to follow their usual practice, as training might 
have altered these practices and been seen as a biasing factor.

The primary objective of the BRIDGE-II-Mix study was to establish the frequency of depressive mixed states by analyzing all the relevant symptoms of either pole. The frequency of depressive mixed states was post hoc defined as (i) the proportion of patients fulfilling the DSM-5 criteria for MDE with mixed features (DSM-5-MXS) (16), or (ii) research-based diagnostic criteria for depressive mixed states (RBDC-MXS). RBDC-MXS are defined by the presence of MDE plus three of the following 14 hypomanic symptoms for at least a week: irritable mood, emotional/mood lability, distractibility, psychomotor agitation, impulsivity, aggression (verbal or physical), racing thoughts, more talkative/pressure to keep talking, hyperactivity, increased energy, risky behavior, grandiosity, elation and hypersexuality. The proportion of patients fulfilling the criteria for BD according to the DSM-IV-TR and bipolarity specifier proposed by Angst et al. $(27,28)$ was also identified.

The objective of the present analysis of the BRIDGE-II-Mix study data was to assess the specific features of patients with (MDE-A) or without (MDE-N) aggressiveness.

An operational clinical definition of aggressiveness has been used, defined by the presence of at least one of the following behaviors during the index MDE: 1. Physical Aggressiveness (PHY): a. ever threatened or b. hit people, or c. got into fights more than most people or $\mathrm{d}$. become so mad to have broken things; 2. Verbal Aggressiveness (VER): a. to argue a lot with other people, or b. to can't help getting into arguments when people disagree, or c. to get very angry for no good reason with troubles in self-controlling. 


\section{Statistical analysis}

The Chi-square test was used for comparison between groups for categorical variables and Student's t-test for continuous variables. The bivariate analysis involved many tests of statistical significance, raising the problem of type I errors. For this reason, we corrected for multiple comparisons and utilized a Bonferroni-corrected threshold for statistical significance, including in the logistic regression only those clinically sound variables under this threshold of 0.004. A stepwise backward logistic regression model was then used to identify the association between aggressiveness and 10 significant variables (BD diagnosis, DSM-5-MXS, severity of mania, comorbid BPD, comorbid substance abuse, lifetime suicide attempts, psychotic features, marked impairment in functioning, no psychiatric treatment, age at first depressive episode). The presence of mixed features in this post-hoc analysis was defined according to the DSM-5 mixed specifier (DSM-5-MXS). The stepwise modeling procedure started with the full model and consisted, for each step, in eliminating the least statistically significant variable from the model and re-computing the revised model, until all remaining variables were at $\mathrm{p}<0.1$. Odds ratios with $95 \%$ confidence intervals were used for observed associations. All tolerance values in the regression analyses were $>0.2$ and all variance inflation factors were $<2$, thereby indicating that multicollinearity was not a source of bias in the regression models (29). Statistical analyses were performed using the Statistical Package for Social Sciences (Statistical Package for Social Science-SPSS, 23.0 version for Windows Inc., Chicago, IL, USA). All p values were two-tailed and statistical significance was set at $\mathrm{p}<0.05$.

\section{Results}

Clinical features: $M D E-A$ patients versus $M D E-N$ patients 
From a total sample of 2,811 patients, 399 (14.2\%) presented verbal or physical aggressiveness (MDE-A group) during the index MDE. The socio-demographic and clinical features are reported in Table $\mathbf{1 .}$

Patients in the MDE-A group were diagnosed more frequently with BD $(<0.001)$, in particular BD-I $(<0.001)$ but not BD-II (0.997), than those in the MDE-N group (see Table 1). The presence of aggressiveness was negatively associated with the diagnosis of unipolar depression $(\mathrm{p}<0.001)$. MDE-A group more frequently presented DSM-5-MXS than MDE-N group ( $<<0.001)$.

Patients in the MDE-A group showed higher rates of comorbid disorders compared to those in the MDE-N group such as: BPD $(\mathrm{p}<0.001)$, anxiety disorder $(\mathrm{p}<0.001)$, eating disorders $(\mathrm{p}=0.003)$ and attention-deficit hyperactivity disorder $(\mathrm{ADHD})(\mathrm{p}=0.011)$.

Patients in the MDE-A reported more frequently a current substance abuse $(\mathrm{p}=0.003)$ but not a current alcohol abuse $(\mathrm{p}=0.086)$ than those in the MDE-N group (see Table 1). In both cases the alcohol or substance abuse was not in the context of dependence of alcohol (67.2\% versus $61 \%, \mathrm{p}=0.022)$ or substance $(66.9 \%$ versus 61.4\%, $\mathrm{p}=0.04$ ) dependence. Patients in the MDE-A group more frequently reported recurrent alcohol- $(2.8 \%$ versus $0.8 \%, \mathrm{p}=0.002)$ and substance-related ( $2 \%$ versus $0.2 \%$, $\mathrm{p}<0.001$ ) legal problems compared to patients in the MDE-N group.

\section{Functioning and severity of patients in the MDE-A group}

The severity of depression ( $\mathrm{p}=0.044)$, mania $(\mathrm{p}<0.001)$ and overall $\mathrm{BD}(\mathrm{p}<0.001)$ were significantly higher in the MDE-A group compared with the MDE-N group. The GAF score was significantly lower in the MDE-A group than in the MDE-N group $(p=0.015)$ (see Table 1). 
Patients in the MDE-A group presented with more marked impairment in social/occupational functioning $(49.6 \%$ versus $24 \%, \mathrm{p}<0.001)$ than patients in the MDE-N group.

The presence of psychotic symptoms was more represented in the MDE-A group than in the MDE-N group (15.5\% versus 7\%, $\mathrm{p}<0.001)$.

Lifetime psychiatric history characteristics of patients in the MDE-A group Age at first psychiatric symptoms $(\mathrm{p}<0.001)$ and age at first depressive episode $(\mathrm{p}<0.001)$ was significantly lower in patients in the MDE-A group (see Table 1).

The total number of mood episodes was significantly higher in patients in the MDE-A group $(\mathrm{p}=0.006)$.

The presence of previous suicide attempts (31.6\% versus $20.8 \%, \mathrm{p}<0.001$ ) was more frequently reported in the MDE-A group.

Patients in the MDE-A group more frequently had a family member requiring treatment $(32.1 \%$ versus $18.8 \%, \mathrm{p}<0.001)$ or a first degree relative with $\mathrm{BD}(22.1 \%$ versus $14.2 \%, \mathrm{p}<0.001$ ) than those in the MDE-N group.

\section{Current psychiatric treatment}

Patients in the MDE-A group were more frequently without any psychiatric treatment than those in the MDE-N group ( $\mathrm{p}=0.004)$ (see Table 1).

MDE-A patients were more frequently under treatment with antipsychotics $(p=0.044)$, mood stabilizers $(p<0.001)$ or electroconvulsive treatment $(E C T)(p<0.001)$ than patients in the MDE-N group.

Patients in the MDE-A group were less frequently prescribed with antidepressants (ADs) than those in the MDE-N group $(<0.001)$; however, in those 
taking $\mathrm{ADs}$, an $\mathrm{AD}$-induced hypomania/mania during the current $\mathrm{MDE}$ was more frequently observed in the MDE-A group than in the MDE-N group (23.1\% versus $15.9 \%, \mathrm{p}<0.001)$.

\section{Clinical variables associated with aggressiveness}

After performing a stepwise backward multivariate modeling procedure $\left(\chi^{2}(8)=300.695\right.$, $\mathrm{p}<0.001$ ), the model explained between 10.6\% (COX and Snell R Square) and $18.9 \%$ (Nagelkerke R Square) of the variance and statistical significance persisted for: age at first depressive episode $(\mathrm{p}<0.001)$, negatively correlated with aggressiveness; severity of mania ( $\mathrm{p}=0.031)$; diagnosis of BD $(\mathrm{p}=0.001)$; comorbidity with $\mathrm{BPD}(\mathrm{p}<0.001)$ but not with substance abuse $(\mathrm{p}=0.633)$; absence of current psychiatric treatments $(\mathrm{p}<0.001)$; presence of psychotic symptoms $(\mathrm{p}=0.007)$; marked impairment in social/occupational functioning $(\mathrm{p}=0.002)$ that were positively correlated with aggressiveness. DSM.5-MXS was the variable most significantly associated with aggressiveness $(\mathrm{p}<0.001, \mathrm{OR}=3.8)$ (see Figure 1).

In order to control for the possible bias of impulsivity-mediated components influencing the association between bipolarity and aggressive behaviors, we performed a second stepwise backward multivariate modeling procedure $\left(\chi^{2}(8)=275.677, \mathrm{p}<0.001\right)$, excluding the variable of BPD comorbidity. The model explained between 9.7\% (COX and Snell R Square) and 17.4\% (Nagelkerke R Square) of the variance. DSM-5-MXS still remained the highest significant association with aggressiveness $(p<0.001$, $\mathrm{OR}=3.9)$. Also, the association with BD diagnosis still remained significant $(\mathrm{p}=0.002$, $\mathrm{OR}=1.6$ ) whilst the presence of lifetime suicide attempts became significant at the logistic regression ( $\mathrm{p}=0.013, \mathrm{OR}=1.4)$ (see Figure 2 ). 


\section{Discussion}

In this multinational sample of 2,811 patients with MDE, a prevalence of aggressive behaviors of $14.2 \%$ was found. The detected prevalence is slightly higher than that found in previous large epidemiological studies (30).

Almost one in four BD patients in our study presented physical or verbal aggressiveness during a MDE. This is in line with the results of previous findings supporting the quite frequent association between aggressiveness and BD (11,30-32).

In general, the presence of aggressiveness during a MDE was associated with a higher severity of manic and depressive episodes. This emerged from both psychometric and clinical assessment, and included higher rates of psychiatric comorbidities, more affective episodes, higher frequencies of lack of psychiatric treatment, greater impairment in global social/occupational functioning, more frequent psychotic symptoms and higher rates of previous suicide attempts. Similar findings were reported in previous studies $(13,23,33)$, showing that the presence of aggressive behaviors had a significant impact on the clinical outcome of the BD illness, with major implications in terms of management and treatment strategies.

Several findings from the present study seem to support that the presence of aggressive behaviors in the MDE-A group was associated with bipolarity. First, significantly higher frequencies of BD diagnosis were found in depressed patients with aggressiveness, whilst a diagnosis of unipolar depression was negatively correlated with aggressive behaviors. This is consistent with previous reports of a higher association between aggressiveness and BD depression compared to unipolar depression (11). The MDE-A group showed higher rates of family history for $\mathrm{BD}$ as well as younger age at the first depressive episode, which represent the most relevant clinical indicators of 
unrecognized bipolarity in depressed patients (27,34-36).

Interestingly, the presence of mixed features during the current MDE was significantly more common in MDE-A patients compared with depressed patients without aggressive behaviors. This is in line with current views on the spectrum of mixed states (37). Hence, several reports showed that the presence of mixed features during a MDE might be considered as a clinical indicator of bipolarity (38-40). The higher rates of mixed features in our depressed patients with aggressive behaviors seem to further support the inclusion of aggressiveness in the BD rubric and within the pool of mixed features during a MDE. This is in accord with the results of a previous study which found that the dimension "Feel angry", as assessed by the Multiple Visual Analog Scales of Bipolarity (MVAS-BP) was the second most frequent (49,5\%) bipolar dimension among the mixed depressive patients (41).

As for psychiatric treatment, in the present sample, MDE-A patients had lower rates of $\mathrm{AD}$ use compared with patients without aggressiveness. Nevertheless, the MDE-A patients treated with ADs showed significantly higher rates of AD-induced mania/hypomania compared with patients without aggressiveness, which represents another strong indicator of bipolarity (20,21,27,34,35,37,42-45).

As expected, when considering comorbid psychiatric diagnoses, we found that MDE-A patients had higher rates of psychiatric comorbidity, indicating a more severe and difficult-to-treat condition. In particular, the comorbidity with BPD and substance abuse were significantly more reported in depressed patients with aggressiveness. Previous studies found that the presence of comorbid BPD could have an independent predictive value in determining trait aggressiveness in patients with BD (13). It has been supposed that the link between BD, BPD, substance abuse and aggressiveness involves the role of impulsivity $(13,46)$, indicating that aggressive 
behaviors could be more associated with impulsive-related comorbidities than with bipolar illness itself. Nonetheless, in order to control for the possible bias of impulsivity-mediated components influencing the association between bipolarity and aggressive behaviors, we excluded the variable of BPD comorbidity from the second stepwise multivariate modeling procedure (the variable substance abuse yet resulted to not be significantly correlated with aggressiveness in the first logistic regression). Interestingly, the significance persisted for all the variables considered in the first modeling, with DSM-5 mixed features becoming the most significant variable associated with aggressiveness.

Surprisingly, the presence of lifetime suicide attempts became significant at the logistic regression, when BPD comorbidity was excluded in the second model (see Figure 2). These results support our hypothesis that aggressiveness could be associated with bipolarity per se, independently from comorbid disorders such as BPD and substance abuse.

The role of aggressiveness in suicidal behaviors has been investigated in several studies. Oquendo and colleagues (47) found higher lifetime aggressiveness in BD patients with a history of suicide attempts compared with BD non-attempters. The same authors (48) reported that aggressive traits besides other clinical factors contribute to predict future suicidal behaviors both in depressed BD and MDD individuals. Moreover, impulsivity was found to be a reliable predictor of suicide risk in BD and MDD patients not as a single trait but only in association with aggressiveness $(33,49,50)$. In this context, aggressiveness could be seen as a part of the construct associated with suicidal behaviors in depressed BD and MDD patients. Furthermore, in our study the presence of DSM-5 mixed features was the variable most significantly associated with aggressiveness. Previous studies found that the presence of DSM-5 
mixed features at the index episode was probably the most important risk factor for suicidality $(37,51)$ and partly contributed to the increased risk of suicide observed in BD-II compared to unipolar depression (52).

Regarding treatment considerations, recent guidelines recommend the need for the early detection of aggressive behaviors in mood disorders (53-55). In our sample, the MDE-A group presented higher rates of psychotic symptoms and more severe mania, together with higher rates of no current pharmacological treatment. Furthermore, the MDE-A group showed higher rates of AD-induced hypomania/mania. Several reports suggest that a prompt therapeutic strategy should be considered to prevent aggressiveness in those patients with higher risk factors, such as severe manic, psychotic symptoms and lifetime history of self-aggressive behaviors $(56,57)$. Taken together, these results claim for the need of an "anti-aggressive” treatment strategy in this subgroup of $\mathrm{BD}$ patients. Moreover, AD monotherapy should be avoided and a combination treatment with mood stabilizers and/or antipsychotics should be considered (58).

The main strengths of the BRIDGE-II-Mix study include the large sample size, and the wide range of care settings, both hospital and community, from eight countries across three continents. Furthermore, narrow exclusion criteria increase the generalizability of the findings. The first limitation is the widely varying rates of hospitalized patients across countries, ranging from $1.0 \%$ to $57.8 \%$, which reflect economically driven policies on the use of hospitalization-based treatment. A second limitation is that the participating centers were not randomly selected, which may have led to a bias through the inclusion of psychiatrists with a particular interest in bipolar spectrum disorders. This may be seen, however, as a positive point, in the sense that some expertise is 
needed to detect past hypomania in MDE patients. Indeed, in the present study aggressiveness in the MDE-A group was assessed retrospectively with high subjectivity of the original rating performed by trained psychiatrists (59). This means that the definition of aggressiveness relies just on retrospectively coded criteria and selected variables already collected in the dataset, rather than ad-hoc variables fetched using validated ratings. This may introduce a measurement bias, especially considering that the operational definition of aggressiveness adopted is a clinical one.

Moreover, there is a need for additional correlation analyses regarding the relationship between aggressiveness and mixed features, controlling for potential confounders to be included in future longitudinal prospective studies using external validators.

In conclusion, aggressiveness might not only be state-related but also a trait component of bipolarity and a diagnostic indicator of mixicity in patients with MDE. Moreover, the association of aggressiveness and the presence of mixed features in depressed patients could represent an indicator of increased risk for suicidal behaviors. Taken together, these results might have important implications in terms of the reconsideration of aggressiveness for diagnostic criteria for the mixed features specifier. Finally, the detection of aggressiveness in MDEs could help in establishing a therapeutic strategy aimed at reducing aggressiveness and preventing suicidal tendencies in the perspective of a personalized pharmacological treatment for this subtype of patients. 


\section{References}

1. Moyer KE. The psychobiology of aggression. Harper \& R. New York; 1976.

2. Safer DJ. Irritable mood and the Diagnostic and Statistical Manual of Mental Disorders. Child Adolesc Psychiatry Ment Health [Internet]. 2009 Oct 24 [cited 2017 Apr 7];3(1):35. Available from:

http://capmh.biomedcentral.com/articles/10.1186/1753-2000-3-35

3. Dolenc B, Dernovšek MZ, Sprah L, Tavcar R, Perugi G, Akiskal HS. Relationship between affective temperaments and aggression in euthymic patients with bipolar mood disorder and major depressive disorder. J Affect Disord [Internet]. 2015 Mar [cited 2017 Apr 7];174:13-8. Available from: http://linkinghub.elsevier.com/retrieve/pii/S0165032714007083

4. Ballester J, Goldstein B, Goldstein TR, Yu H, Axelson D, Monk K, et al. Prospective longitudinal course of aggression among adults with bipolar disorder. Bipolar Disord [Internet]. 2014 May [cited 2017 Apr 7];16(3):262-9. Available from: http://doi.wiley.com/10.1111/bdi.12168

5. Ng TH, Freed RD, Titone MK, Stange JP, Weiss RB, Abramson LY, et al. Aggression Protects Against the Onset of Major Depressive Episodes in Individuals With Bipolar Spectrum Disorder. Behav Ther [Internet]. 2017 May [cited 2017 Apr 12];48(3):311-21. Available from: http://linkinghub.elsevier.com/retrieve/pii/S0005789416300557

6. Maj M, Pirozzi R, Magliano L, Bartoli L. Agitated depression in bipolar I disorder: prevalence, phenomenology, and outcome. Am J Psychiatry [Internet]. 2003 Dec [cited 2017 Apr 7];160(12):2134-40. Available from: http://psychiatryonline.org/doi/abs/10.1176/appi.ajp.160.12.2134 
7. Sato T, Bottlender R, Kleindienst N, Möller H-J. Syndromes and phenomenological subtypes underlying acute mania: a factor analytic study of 576 manic patients. Am J Psychiatry [Internet]. 2002 Jun [cited 2017 Apr 7];159(6):968-74. Available from: http://psychiatryonline.org/doi/abs/10.1176/appi.ajp.159.6.968

8. Michaelis BH, Goldberg JF, Davis GP, Singer TM, Garno JL, Wenze SJ. Dimensions of impulsivity and aggression associated with suicide attempts among bipolar patients: a preliminary study. Suicide Life Threat Behav [Internet]. 2004 Jun [cited 2017 Apr 7];34(2):172-6. Available from: http://www.extenza-eps.com/GPI/doi/abs/10.1521/suli.34.2.172.32783

9. Ballester J, Goldstein T, Goldstein B, Obreja M, Axelson D, Monk K, et al. Is bipolar disorder specifically associated with aggression? Bipolar Disord [Internet]. 2012 May [cited 2017 Apr 7];14(3):283-90. Available from: http://www.ncbi.nlm.nih.gov/pubmed/22548901

10. Barlow K, Grenyer B, Ilkiw-Lavalle O. Prevalence and precipitants of aggression in psychiatric inpatient units. Aust N Z J Psychiatry [Internet]. 2000 Dec [cited 2017 Apr 7];34(6):967-74. Available from: http://journals.sagepub.com/doi/10.1080/000486700271

11. Dervic K, Garcia-Amador M, Sudol K, Freed P, Brent DA, Mann JJ, et al. Bipolar I and II versus unipolar depression: clinical differences and impulsivity/aggression traits. Eur Psychiatry [Internet]. 2015 Jan [cited 2017 Apr 7];30(1):106-13. Available from: http://linkinghub.elsevier.com/retrieve/pii/S0924933814001370

12. Salloum IM, Cornelius JR, Mezzich JE, Kirisci L. Impact of concurrent alcohol misuse on symptom presentation of acute mania at initial evaluation. Bipolar 
Disord [Internet]. 2002 Dec [cited 2017 Apr 7];4(6):418-21. Available from: http://www.ncbi.nlm.nih.gov/pubmed/12519103

13. Garno JL, Gunawardane N, Goldberg JF. Predictors of trait aggression in bipolar disorder. Bipolar Disord [Internet]. 2008;10(2):285-92. Available from: http://www.ncbi.nlm.nih.gov/pubmed/18271908

14. Cassidy F, Forest K, Murry E, Carroll BJ. A factor analysis of the signs and symptoms of mania. Arch Gen Psychiatry [Internet]. 1998 Jan [cited 2017 Apr 7];55(1):27-32. Available from: http://www.ncbi.nlm.nih.gov/pubmed/9435757

15. Pacchiarotti I, Nivoli AMA, Mazzarini L, Kotzalidis GD, Sani G, Koukopoulos A, et al. The symptom structure of bipolar acute episodes: in search for the mixing link. J Affect Disord [Internet]. 2013 Jul [cited 2017 Apr 7];149(1-3):5666. Available from: http://www.ncbi.nlm.nih.gov/pubmed/23394711

16. American Psychiatric Association. Diagnostic and statistical manual of mental disorders, 5th edn. American Psychiatric Association (2013) Diagnostic and statistical manual of mental disorders, 5th edn. Washington DC: American Psychiatric Association; 2013.

17. American Psychiatric Association. Diagnostic and statistical manual of mental disorders (3rd ed.). Washington DC; 1980.

18. Vieta E, Valentí M. Mixed states in DSM-5: implications for clinical care, education, and research. J Affect Disord [Internet]. 2013 May 15 [cited 2017 Apr 12];148(1):28-36. Available from:

http://linkinghub.elsevier.com/retrieve/pii/S0165032713002322

19. Vieta E, Grunze H, Azorin J-M, Fagiolini A. Phenomenology of manic episodes according to the presence or absence of depressive features as defined in DSM-5: Results from the IMPACT self-reported online survey. J Affect Disord [Internet]. 
2014 Mar [cited 2017 Apr 12];156:206-13. Available from:

http://linkinghub.elsevier.com/retrieve/pii/S0165032713008847

20. Barbuti M, Pacchiarotti I, Vieta E, Azorin J, Angst J, Bowden C, et al.

Antidepressant-induced hypomania/mania in patients with major depression:

evidence from the BRIDGE-II-MIX study. J Affect Disord. 2017;in press.

21. Perugi G, Angst J, Azorin J-M, Bowden CL, Mosolov S, Reis J, et al. Mixed features in patients with a major depressive episode: the BRIDGE-II-MIX study.

J Clin Psychiatry [Internet]. 2015 Mar 25 [cited 2017 Apr 7];76(3):e351-8.

Available from:

http://www.psychiatrist.com/jcp/article/pages/2015/v76n03/v76n0316.aspx

22. Perugi G, Angst J, Azorin J-M, Bowden CL, Caciagli A, Mosolov S, et al.

Relationships between mixed features and borderline personality disorder in 2811 patients with major depressive episode. Acta Psychiatr Scand [Internet]. 2016 Feb [cited 2017 Apr 7];133(2):133-43. Available from:

http://doi.wiley.com/10.1111/acps.12457

23. Popovic D, Vieta E, Azorin J-M, Angst J, Bowden CL, Mosolov S, et al. Suicide attempts in major depressive episode: evidence from the BRIDGE-II-Mix study. Bipolar Disord [Internet]. 2015 Nov [cited 2017 Apr 7];17(7):795-803.

Available from: http://doi.wiley.com/10.1111/bdi.12338

24. American Psychiatric Association. Diagnostic and statistical manual of mental disorders (4th ed., Text Revision). Washington, DC: Author.; 2000.

25. Endicott J, Spitzer RL, Fleiss JL, Cohen J. The global assessment scale. A procedure for measuring overall severity of psychiatric disturbance. Arch Gen Psychiatry [Internet]. 1976 Jun [cited 2017 Apr 7];33(6):766-71. Available from: http://www.ncbi.nlm.nih.gov/pubmed/938196 
26. Spearing MK, Post RM, Leverich GS, Brandt D, Nolen W. Modification of the Clinical Global Impressions (CGI) Scale for use in bipolar illness (BP): the CGIBP. Psychiatry Res [Internet]. 1997 Dec 5 [cited 2017 Apr 7];73(3):159-71. Available from: http://www.ncbi.nlm.nih.gov/pubmed/9481807

27. Angst J, Azorin J-M, Bowden CL, Perugi G, Vieta E, Gamma A, et al. Prevalence and characteristics of undiagnosed bipolar disorders in patients with a major depressive episode: the BRIDGE study. Arch Gen Psychiatry [Internet]. 2011 Aug 1 [cited 2017 Apr 7];68(8):791-8. Available from: http://archpsyc.jamanetwork.com/article.aspx?doi=10.1001/archgenpsychiatry.20 11.87

28. Angst J, Gamma A, Bowden CL, Azorin JM, Perugi G, Vieta E, et al. Evidencebased definitions of bipolar-I and bipolar-II disorders among 5,635 patients with major depressive episodes in the Bridge Study: validity and comorbidity. Eur Arch Psychiatry Clin Neurosci [Internet]. 2013 Dec 31 [cited 2017 Apr 7];263(8):663-73. Available from: http://link.springer.com/10.1007/s00406-0130393-4

29. Yoo W, Mayberry R, Bae S, Singh K, Peter He Q, Lillard JW. A Study of Effects of MultiCollinearity in the Multivariable Analysis. Int J Appl Sci Technol [Internet]. 2014 Oct [cited 2016 Apr 4];4(5):9-19. Available from: http://www.pubmedcentral.nih.gov/articlerender.fcgi?artid=4318006\&tool=pmce ntrez\&rendertype=abstract

30. Corrigan PW, Watson AC. Findings from the National Comorbidity Survey on the frequency of violent behavior in individuals with psychiatric disorders. Psychiatry Res [Internet]. 2005;136(2-3):153-62. Available from: http://www.ncbi.nlm.nih.gov/pubmed/16125786 
31. Grant BF, Stinson FS, Hasin DS, Dawson DA, Chou SP, Ruan WJ, et al. Prevalence, correlates, and comorbidity of bipolar I disorder and axis I and II disorders: results from the National Epidemiologic Survey on Alcohol and Related Conditions. J Clin Psychiatry [Internet]. 2005 Oct [cited 2017 Apr 7];66(10):1205-15. Available from:

http://www.ncbi.nlm.nih.gov/pubmed/16259532

32. Látalová K. Bipolar disorder and aggression. Int J Clin Pract. 2009;63(6):889-99.

33. Perroud N, Baud P, Mouthon D, Courtet P, Malafosse A. Impulsivity, aggression and suicidal behavior in unipolar and bipolar disorders. J Affect Disord [Internet]. 2011 Nov [cited 2017 Apr 7];134(1-3):112-8. Available from: http://linkinghub.elsevier.com/retrieve/pii/S0165032711003107

34. Angst J, Cui L, Swendsen J, Rothen S, Cravchik A, Kessler RC, et al. Major Depressive Disorder With Subthreshold Bipolarity in the National Comorbidity Survey Replication. Am J Psychiatry [Internet]. 2010 Oct [cited 2017 Apr 7];167(10):1194-201. Available from: http://psychiatryonline.org/doi/abs/10.1176/appi.ajp.2010.09071011

35. Angst J, Gamma A, Bowden CL, Azorin JM, Perugi G, Vieta E, et al. Diagnostic criteria for bipolarity based on an international sample of 5,635 patients with DSM-IV major depressive episodes. Eur Arch Psychiatry Clin Neurosci [Internet]. 2012 Feb 5 [cited 2017 Apr 7];262(1):3-11. Available from: http://link.springer.com/10.1007/s00406-011-0228-0

36. Benazzi F, Akiskal HS. How best to identify a bipolar-related subtype among major depressive patients without spontaneous hypomania: superiority of age at onset criterion over recurrence and polarity? J Affect Disord [Internet]. 2008 Apr [cited 2017 Apr 7];107(1-3):77-88. Available from: 
http://linkinghub.elsevier.com/retrieve/pii/S0165032707002935

37. Solé E, Garriga M, Valentí M, Vieta E. Mixed features in bipolar disorder. CNS Spectr [Internet]. 2016 Dec 29 [cited 2017 Apr 7];1-7. Available from: http://www.ncbi.nlm.nih.gov/pubmed/28031070

38. Takeshima M, Oka T. DSM-5-defined “mixed features” and Benazzi’s mixed depression: Which is practically useful to discriminate bipolar disorder from unipolar depression in patients with depression? Psychiatry Clin Neurosci [Internet]. 2015 Feb [cited 2017 Apr 7];69(2):109-16. Available from: http://doi.wiley.com/10.1111/pcn.12213

39. Iwanami T, Maeshima H, Baba H, Satomura E, Namekawa Y, Shimano T, et al. Psychomotor agitation in major depressive disorder is a predictive factor of mood-switching. J Affect Disord [Internet]. 2015 Jan [cited 2017 Apr 7];170:185-9. Available from:

http://linkinghub.elsevier.com/retrieve/pii/S0165032714005461

40. McIntyre RS, Soczynska JK, Cha DS, Woldeyohannes HO, Dale RS, Alsuwaidan MT, et al. The prevalence and illness characteristics of DSM-5defined \&quot;mixed feature specifier\&quot; in adults with major depressive disorder and bipolar disorder: Results from the International Mood Disorders Collaborative Project. J Affect Disord [Internet]. 2015 Feb 1 [cited 2017 Apr 7];172:259-64. Available from: http://linkinghub.elsevier.com/retrieve/pii/S0165032714005801

41. Azorin J-M, Kaladjian A, Adida M, Fakra E, Belzeaux R, Hantouche E, et al. Self-assessment and characteristics of mixed depression in the French national EPIDEP study. J Affect Disord [Internet]. 2012 Dec 20 [cited 2017 May 2];143(1-3):109-17. Available from: 
http://linkinghub.elsevier.com/retrieve/pii/S0165032712003916

42. Sani G, Napoletano F, Vöhringer PA, Sullivan M, Simonetti A, Koukopoulos A, et al. Mixed Depression: Clinical Features and Predictors of Its Onset Associated with Antidepressant Use. Psychother Psychosom [Internet]. 2014 [cited 2017 Apr 7];83(4):213-21. Available from:

http://www.ncbi.nlm.nih.gov/pubmed/24970376

43. Koukopoulos A, Sani G, Koukopoulos AE, Manfredi G, Pacchiarotti I, Girardi P. Melancholia agitata and mixed depression. Acta Psychiatr Scand Suppl [Internet]. 2007 Feb [cited 2017 Apr 7];115(433):50-7. Available from: http://doi.wiley.com/10.1111/j.1600-0447.2007.00963.x

44. Vieta E, Garriga M. Adjunctive antidepressants in bipolar depression. The Lancet Psychiatry [Internet]. 2016 Dec [cited 2017 Apr 7];3(12):1095-6. Available from: http://www.ncbi.nlm.nih.gov/pubmed/28100424

45. Pacchiarotti I, Bond DJ, Baldessarini RJ, Nolen WA, Grunze H, Licht RW, et al. The International Society for Bipolar Disorders (ISBD) task force report on antidepressant use in bipolar disorders. Am J Psychiatry [Internet]. 2013 Nov [cited 2016 May 13];170(11):1249-62. Available from: http://www.pubmedcentral.nih.gov/articlerender.fcgi?artid=4091043\&tool=pmce ntrez\&rendertype $=$ abstract

46. Swann AC, Lijffijt M, Lane SD, Steinberg JL, Moeller FG. Interactions between bipolar disorder and antisocial personality disorder in trait impulsivity and severity of illness. Acta Psychiatr Scand [Internet]. 2010 Jun [cited 2016 Feb 16];121(6):453-61. Available from: http://www.pubmedcentral.nih.gov/articlerender.fcgi?artid=2911146\&tool=pmce ntrez\&rendertype=abstract 
47. Oquendo MA, Waternaux C, Brodsky B, Parsons B, Haas GL, Malone KM, et al. Suicidal behavior in bipolar mood disorder: clinical characteristics of attempters and nonattempters. J Affect Disord [Internet]. 2000 Aug [cited 2017 Apr 7];59(2):107-17. Available from: http://www.ncbi.nlm.nih.gov/pubmed/10837879

48. Oquendo MA, Galfalvy H, Russo S, Ellis SP, Grunebaum MF, Burke A, et al. Prospective Study of Clinical Predictors of Suicidal Acts After a Major Depressive Episode in Patients With Major Depressive Disorder or Bipolar Disorder. Am J Psychiatry [Internet]. 2004 Aug [cited 2017 Apr 7];161(8):143341. Available from: http://www.ncbi.nlm.nih.gov/pubmed/15285970

49. Carli V, Jovanović N, Podlesek A, Roy A, Rihmer Z, Maggi S, et al. The role of impulsivity in self-mutilators, suicide ideators and suicide attempters - a study of 1265 male incarcerated individuals. J Affect Disord [Internet]. 2010 Jun [cited 2017 Apr 7];123(1-3):116-22. Available from:

http://linkinghub.elsevier.com/retrieve/pii/S0165032710002533

50. Mann JJ, Arango VA, Avenevoli S, Brent DA, Champagne FA, Clayton P, et al. Candidate Endophenotypes for Genetic Studies of Suicidal Behavior. Biol Psychiatry [Internet]. 2009 Apr 1 [cited 2017 Apr 7];65(7):556-63. Available from: http://www.ncbi.nlm.nih.gov/pubmed/19201395

51. Reinares M, del Mar Bonnín C, Hidalgo-Mazzei D, Undurraga J, Mur M, Nieto E, et al. Making sense of DSM-5 mania with depressive features. Aust New Zeal J Psychiatry [Internet]. 2015 Jun [cited 2017 Apr 7];49(6):540-9. Available from: http://journals.sagepub.com/doi/10.1177/0004867415585583

52. Benazzi F. Reviewing the diagnostic validity and utility of mixed depression (depressive mixed states). Eur Psychiatry [Internet]. 2008 Jan [cited 2017 Apr 
7];23(1):40-8. Available from:

http://linkinghub.elsevier.com/retrieve/pii/S0924933807013600

53. Stahl SM, Morrissette DA, Cummings M, Azizian A, Bader S, Broderick C, et al.

California State Hospital Violence Assessment and Treatment (Cal-VAT)

guideline. CNS Spectr [Internet]. 2014 Oct [cited 2017 Apr 7];19(5):449-65.

Available from: http://www.ncbi.nlm.nih.gov/pubmed/27358935

54. Garriga M, Pacchiarotti I, Kasper S, Zeller SL, Allen MH, Vázquez G, et al. Assessment and management of agitation in psychiatry: Expert consensus. World J Biol Psychiatry [Internet]. 2016 Feb 17 [cited 2017 Apr 12];17(2):86-128. Available from: http://www.tandfonline.com/doi/full/10.3109/15622975.2015.1132007

55. Goodwin G, Haddad P, Ferrier I, Aronson J, Barnes T, Cipriani A, et al. Evidence-based guidelines for treating bipolar disorder: Revised third edition recommendations from the British Association for Psychopharmacology. J Psychopharmacol [Internet]. 2016 Jun [cited 2017 Mar 24];30(6):495-553. Available from: http://www.ncbi.nlm.nih.gov/pubmed/26979387

56. Sahlin H, Kuja-Halkola R, Bjureberg J, Lichtenstein P, Molero Y, Rydell M, et al. Association Between Deliberate Self-harm and Violent Criminality. JAMA Psychiatry [Internet]. 2017 Apr 5 [cited 2017 Apr 7]; Available from: http://www.ncbi.nlm.nih.gov/pubmed/28384711

57. Verdolini N, Murru A, Attademo L, Garinella R, Pacchiarotti I, del Mar Bonnin C, et al. The aggressor at the mirror: Psychiatric correlates of deliberate self-harm in male prison inmates. Eur Psychiatry. 2017;in press.

58. Vieta E. Antidepressants in bipolar I disorder: never as monotherapy. Am J Psychiatry [Internet]. 2014 Oct [cited 2017 Apr 12];171(10):1023-6. Available 
from: http://psychiatryonline.org/doi/abs/10.1176/appi.ajp.2014.14070826

59. Allen DM, Parry PI, Purssey R, Spielmans GI, Jureidini J, Rosenlicht NZ, et al. BRIDGE Study Warrants Critique. Arch Gen Psychiatry [Internet]. 2012 Jun 1 [cited 2017 Jun 22];69(6):643-4-5. Available from:

http://www.ncbi.nlm.nih.gov/pubmed/22664552 
Acknowledgements: the authors thank the support of the Spanish Ministry of Economy and Competitiveness integrated into the Plan Nacional de $\mathrm{I}+\mathrm{D}+\mathrm{I}$ and co-financed by the ISCIII-Subdirección General de Evaluación and the Fondo Europeo de Desarrollo Regional (FEDER); the CIBERSAM (Centro de Investigación Biomédica en Red de Salud Mental); the Secretaria d'Universitats i Recerca del Departament d'Economia i Coneixement (2014_SGR_398) and the CERCA Programme / Generalitat de Catalunya. Funding sources: the sponsor of this study (Sanofi-Aventis) was involved in the study design, conduct, monitoring and preparation of the final database, but not in the content of this report. All investigators recruited received fees from the sponsor in recognition of their participation in the study on a per-patient basis. The corresponding author had full access to all the data and had final responsibility for data analyses, preparation of the report and the decision to submit for publication.

\section{Conflicts of interest:}

Dr. Verdolini has no conflict of interest.

Prof. Perugi has acted as consultant of Eli Lilly, Lundbeck, Angelini; received grant/research support from Lundbeck; is on the speaker/advisory board of SanofiAventis, Eli Lilly, Lundbeck, FB-Health, Angelini.

Dr. Samalin has received grants, honoraria, or consulting fees from AstraZeneca, Bristol-Myers Squibb, Janssen-Cilag, Lundbeck, Otsuka, Sanofi-Aventis, and Takeda. Dr. Murru has served as a consultant, adviser, or speaker for Adamed, AstraZeneca, Bristol-Myers Squibb, Janssen-Cilag, Lundbeck, Otsuka, and Sanofi-Aventis.

Prof. Angst has served on the advisory board for Eli Lilly \& Company, Janssen Cilag, Lundbeck, on the speakers’ bureau for Eli Lilly \& Company, Lundbeck, AstraZeneca and Bristol-Myers Squibb, and as a consultant for Sanofi-Aventis. 
Prof. Azorin has received research support and has acted as a consultant and/or served on a speaker’s bureau for Janssen, Lundbeck, Otsuka, Roche, Servier and Takeda.

Prof. Bowden has received grant support from Sunovion and the NIMH, and has consulted for Takeda.

Prof. Mosolov has received research grants from, and been involved in clinical trials for Servier, Eli Lilly, Lundbeck, AstraZeneca, Janssen-Cilag, Sanofi-Aventis, Geodon Richter, Stada and Amgen; has been a speaker for Sanofi-Aventis, AstraZeneca, Bristol Myers Squibb, Janssen-Cilag, Pfizer, Novartis, GlaxoSmithKline and Servier; and was an advisory board member for Medavante.

Prof. Young declares no conflict of interests.

Dr. Barbuti has no conflict of interest.

Dr. Guiso has no conflict of interest.

Dr. Popovic has served as a speaker, medical writer or has participated in advisory boards for Bristol-Myers Squibb, Merck Sharp \& Dohme, Janssen-Cilag, Ferrer and Forum Pharmaceuticals.

Prof. Vieta has received research support from or served as consultant, adviser or speaker for AB-Biotics, Alexza, Almirall, Allergan, AstraZeneca, Bristol-Myers Squibb, Dainippon Sumitomo Pharma, Elan, Eli Lilly, Ferrer, Forest Research Institute, 7th Framework Program of the European Union,Geodon Richter, GlaxoSmithKline, Janssen-Cilag, Jazz, Lundbeck, Merck, Novartis,Organon, Otsuka, Pfizer, Roche, Sanofi-Aventis, Servier, Solvay, Shire, Spanish Ministry of Science and Innovation, Sunovion, Stanley Medical Research Institute, Takeda, Teva, United Biosource Corporation and Wyeth.

Dr. Pacchiarotti has received CME-related honoraria, or consulting fees from ADAMED, Janssen-Cilag and Lundbeck. 